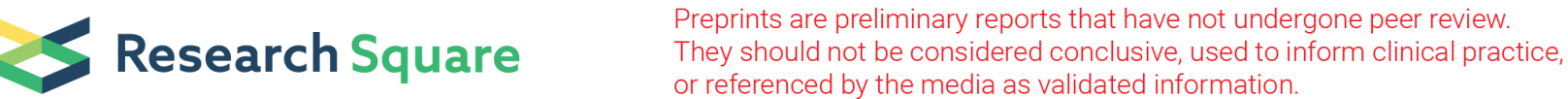

\section{Application of Factorial Design In The Optimization of A Procedure For Antimony (Sb) Remediation From Wastewater Employing Mesoporous Array}

José Arnaldo Santana Costa ( $\sim$ josearnaldo23@yahoo.com.br)

Universidade Federal de Sao Carlos Centro de Ciencias Exatas e de Tecnologia https://orcid.org/00000002-2354-1163

\section{Vinicius Câmara Costa}

Embrapa Instrumentacao

\section{Matheus Lima de Mello}

Federal University of Sao Carlos: Universidade Federal de Sao Carlos

\section{Caio Marcio Paranhos}

Federal University of Sao Carlos: Universidade Federal de Sao Carlos

\section{Research Article}

Keywords: Nanostructured mesoporous material, sustainable approach, factorial design, antimony remediation

Posted Date: June 30th, 2021

DOI: https://doi.org/10.21203/rs.3.rs-623255/v1

License: (c) (i) This work is licensed under a Creative Commons Attribution 4.0 International License. Read Full License 


\section{Abstract}

This study describes the sustainable and eco-friendly synthesis of the silica-based mesoporous structure from the use of alternative amorphous silica extracted from rice husk ash (RHA). The mesoporous material was called MCM-48 (RHA) and its application as adsorbent to the antimony ( $\mathrm{Sb}$ ) remediation in wastewater was tested. The adsorbent was prepared by an efficient and sustainable hydrothermal method, which exhibited an amorphous framework with type IV isotherms and type $\mathrm{H} 1$ hysteresis, high surface area $\left(820.94 \mathrm{~m}^{2} \mathrm{~g}^{-1}\right)$ and total pore volume $\left(0.55 \mathrm{~cm}^{3} \mathrm{~g}^{-1}\right)$ with a narrow mesopores distribution, uniform spherical particles, and well-defined architecture. Multivariate optimization using a factorial design $\left(2^{4}\right)$ was employed in the adsorption tests of $\mathrm{Sb}$. The variables evaluated and the conditions selected were: adsorbent mass ( $45 \mathrm{mg}$ ); adsorption time (60 min); $\mathrm{pH}$ (ranged from 2 to 10); and concentration of the Sb standard $\left(8 \mathrm{~mol} \mathrm{~L}^{-1}\right)$. The adsorbent material proposed in this study proved to be efficient for $\mathrm{Sb}$ remediation in aqueous media, mainly because it is a material with easy access, low-cost, and eco-friendly.

\section{Highlights}

- The sustainable and eco-friendly synthesis of MCM-48 mesoporous arrays.

- Use of RHA as an alternative and inexpensive silicon source.

- The MCM-48 exhibited large surface area and total pore volume.

- The MCM-48 exhibited a high removal efficiency of Sb.

\section{Introduction}

Industrial waste, commonly thrown into aquatic environments, contains both inorganic and organic contaminants, representing a global concern for many countries (Akhil et al. 2021). Among the various inorganic contaminants, antimony $(\mathrm{Sb})$ is considered pollutant non-biodegradable and that can cause many environmental damages. Furthermore, carcinogenic contaminants cause health problems, especially for human beings (Viczek et al. 2020). The main industrial activities that can contribute to the discharge $\mathrm{Sb}$ in aquatic environments come from the industries of fire retardants, pigments, mining, and ceramics (Aquino et al. 2016; Chu et al. 2019; Meng et al. 2020). Some countries, such as China, Grace, and India, have suffered with problems of contamination in groundwater by $\mathrm{Sb}$, which can cause damage to human health (Antoniadis et al. 2019; Xu et al. 2019). In this sense, the development of methodologies that are efficient for the $\mathrm{Sb}$ remediation from wastewater is essential.

Among the various approaches in the literature for the Sb removal (Xiang-Xue et al. 2019; Chen et al. 2020), adsorption technology is most commonly method used, and several adsorbents have been developed (Zhao et al. 2010). Despite the various absorbent materials already available in the literature, it is still necessary to find an absorbent material that has the following characteristics: (i) low-cost, eco- 
friendly, and sustainable; (ii) good physical and chemical stability; (iii) excellent textural and structural features; and (iv) high selectivity, so on (Costa and Paranhos 2020; Costa et al. 2020b). In this context, the synthesis mesoporous materials has attracted a great deal of interest for the adsorption process and has already been used with success for removal of the organic compounds (Santos et al. 2019; Costa et al. 2020d, c, 2021b, a) and inorganic constituents (de Sá et al. 2020; Costa et al. 2020a).

The mesoporous materials were synthesized for the first time in the early 1990s, and have since been used in the most diverse technological applications. The best known and/or studied mesoporous materials are those of the M41S family, represented by MCM-41 (hexagonal phase), MCM-50 (lamellar phase), and MCM-48 (cubic phase) (Costa et al. 2015, 2017a, b; Santos et al. 2019), which is the focus of this approach.

The mesoporous structures have attractive features, such as good thermal and mechanical stability, and high surface area, which allows the diffusion and/or adsorption process of the organic and inorganic compounds through their uniform pores and high mesoporous arrangement, as well as ease in the synthesis and functionalization process of these ordered structures (Costa et al. 2014, 2015, 2017a, b). The silica-based mesoporous arrays are synthesized via the hydrothermal method from the use of a surfactant (directing agent), a catalyst (acid or basic), and mainly from a silica source, which is responsible for forming the framework of the amorphous material (Costa et al. 2015, 2017b).

In the literature there are several works showing the synthesis of these mesoporous materials from the use of the commercial silica sources, mainly tetraethylorthosilicate (TEOS) (Costa et al. 2014, 2017b; Ambursa et al. 2017), silica gel (Santos et al. 2019), and sodium silicate (Costa et al. 2017a; Santos et al. 2019). However, there are some works that show the preparation of the mesoporous structures from the use of the alternative, sustainable, and eco-friendly materials as a silica source, such as fly ash (Castillo et al. 2018), rape straw (Li et al. 2019), straw ash (Ma et al. 2016), bamboo leaf ash (Arumugam et al. 2018), rice husk (Sohrabnezhad and Daraie Mooshangaie 2019), sedge ash (Ghorbani et al. 2013), and sugarcane bagasse (Norsuraya et al. 2016), so on. In the present approach, we use the rice husk ash (RHA) as an alternative, inexpensive, eco-friendly, low-cost, abundant, and accessible source of amorphous silica for the synthesis of the mesoporous material with a cubic phase (MCM-48 (RHA)), which was later used as an adsorbent material in the $\mathrm{Sb}$ removal in aqueous media.

The most of the approaches found in the literature, which are dedicated to the adsorption studies, are carried out from the univariate optimization of the adsorption tests, which aim at understanding the adsorption mechanism between the adsorbent material and the adsorbate, especially from the correlation of experimental adsorption data with kinetic and isothermal theoretical models (Costa et al. 2014; Costa and Paranhos 2019). However, these approaches are laborious and requires expertise analyst.

Recently, a demand has emerged for the optimization step of the procedures are fast and with reduced number of experiments (Ferreira et al. 2018). In this sense, the multivariate optimization techniques have been shown powerful to evaluation the variables that affect the analytical response in order to obtain the best conditions of optimization to ensure the procedure reliability. Among the multivariate optimization 
tools factorial design is more employed and allows a preliminary evaluation of the variables for development of linear models (Costa et al. 2019; Gamela et al. 2020). These tools have numerous advantages, such as: (i) possibility of evaluating synergistic and antagonistic interactions between variables; (ii) possibility of forecasting the system under study in a condition that has not been tested in practice; and (iii) reduces the generation of chemical waste which contributes to the principles of green chemistry (Ferreira et al. 2017; Costa et al. 2018). Factorial designs have been used in several areas, but its use in absorption procedures has not been explored sufficiently.

In this context, the factorial design was employed to optimize a procedure for Sb remediation in wastewater. In addition, the adsorbent material used was obtained from a cleaner, low-cost, and ecofriendly approach from the use of alternative amorphous silica extracted from RHA.

\section{Experimental}

\subsection{Standards, solvents, and reagents}

The rice husk $(\mathrm{RH})$ of agulhinha (Indian origin) variety was received from the Brazilian Agricultural Research Corporation (Embrapa) (São Carlos, São Paulo, Brazil). Details about thermal treatment realized to obtain RHA from RH and characterizations are available in the publication of Costa et al. (2018). Ultrapure water (18.2 M $\Omega \mathrm{cm}$ resistivity) produced by a Milli-Q® Plus Total Water System (Millipore Corp., Bedford, MA, USA) was used to prepare all the solutions. The Sb analytical standards (Qhemis, São Paulo, SP, Brazil), cetyltrimethylammonium bromide (CTAB) (Neon, Suzano, SP, Brazil), sodium hydroxide $(\mathrm{NaOH})$ (Synth, Diadema, SP, Brazil), and chloric acid $(\mathrm{HCl}) 37 \%$ w/v (Synth, Diadema, SP, Brazil) were used during the procedure. All glassware and polypropylene flasks were washed with soap, soaked in $10 \% \mathrm{v} / \mathrm{v}$ nitric acid $\left(\mathrm{HNO}_{3}\right)$ for $24 \mathrm{~h}$, and rinsed with ultrapure water prior to use.

\subsection{Preparation of MCM-48 (RHA) mesoporous array}

The mesoporous array (named MCM-48 (RHA)) was synthesized from RHA of the agulhinha variety. Thus, amorphous silica was extracted from the RHA by leaching with sodium hydroxide solution and the MCM-48 (RHA) was synthesized by a hydrothermal route. The extraction of the sodium silicate solution was performed according to our methodology developed recently (Costa and Paranhos 2018), and the MCM-48 (RHA) was synthesized as follows: (i) $10 \mathrm{~g}$ of CTAB was dissolved in $70 \mathrm{~mL}$ of $\mathrm{NaOH}(0.75 \mathrm{~mol}$ $\mathrm{L}^{-1}$ ) under constant stirring at room temperature for $1 \mathrm{~h}$; (ii) after this time, $50 \mathrm{~mL}$ of the sodium silicate solution from RHA were added slowly into the solution; (iii) therefore, this mixture was stirred at room temperature for $2 \mathrm{~h}$ and then transferred to a Teflon-lined stainless steel autoclave, which was placed in a vacuum oven and heated at $100^{\circ} \mathrm{C}$ for $48 \mathrm{~h}$; (iv) after this time, the solution $\mathrm{pH}$ was adjusted to $\sim 10$ with $\mathrm{HCl}\left(1 \mathrm{~mol} \mathrm{~L}^{-1}\right)$ and the reactor was left in the oven for another $24 \mathrm{~h}$ at $100^{\circ} \mathrm{C}$; $(\mathrm{v})$ the solid product obtained was filtered, washed with deionized water, and dried in a vacuum oven at $100^{\circ} \mathrm{C}$ for $12 \mathrm{~h}$; (vi) finally, CTAB removal was performed by calcination at $550^{\circ} \mathrm{C}$ for $6 \mathrm{~h}$ at a rate of $1^{\circ} \mathrm{C} \mathrm{min}^{-1}$.

\subsection{Characterization of MCM-48 (RHA) adsorbent}


The characterization of the RH and RHA was complemented using Scanning Electron Microscopy/Energy Dispersive X-Ray Spectroscopy (SEM/EDS). The prepared MCM-48 (RHA) was characterized using Fourier transform infrared spectroscopy (FTIR) spectra for powder samples in the form of KBr pastilles achieved in the region of 4000 to $400 \mathrm{~cm}^{-1}$ using a Varian 3100 equipment (at room temperature, 32 scans, and a resolution of $4 \mathrm{~cm}^{-1}$ ). Powder X-ray diffractometry (XRD) analysis was required on a LabX XDR-6000 (Shimadzu) equipment using Cu Ka radiation source $(\lambda=1.5406 \AA)$ at a voltage/current display of 30 $\mathrm{kV} / 30 \mathrm{~mA}$. The data were collected with a diffraction angle $(2 \theta)$ ranging from 5 to $80^{\circ}$ and scanning rate of $2^{\circ} \mathrm{min} \rrbracket^{1}$. SEM analysis was achieved in a FEG-XL30 (Philips) equipment with an EDS accessory, operating with the help of a secondary electron (SE) detector and an accelerator power of at $3 \mathrm{kV}$. Nitrogen adsorption and desorption isotherms of MCM-48 (RHA) (evacuated for $2 \mathrm{~h}$ at $150^{\circ} \mathrm{C}$ ) was acquired using a NOVA 1200 apparatus in the at liquid nitrogen temperature $\left(-196.15^{\circ} \mathrm{C}\right)$. Additionally, the surface area $\left(S_{B E T}\right)$ and the pore size distribution $\left(D_{B J H}\right)$ values were calculated from the adsorption data, using the Brunauer-Emmentt-Teller and the Barrett-Joyner-Halenda methods, respectively.

\subsection{Determination of the $\mathrm{Sb}$}

The Sb concentrations were measured using an inductively coupled plasma optical emission spectrometry (ICP OES) (iCAP 7000, Thermo Scientific, Waltham, MA, USA). Argon gas $(99.996 \%$, White Martins-Praxair, Sertãozinho, SP, Brazil) was used to generate the plasma in all ICP OES measurements. The instrumental conditions were established as the manufacturer recommendations, as being: power $(1.2 \mathrm{~kW})$, plasma gas flow $\left(15.0 \mathrm{~L} \mathrm{~min} \nabla^{1}\right)$, auxiliary gas flow $\left(1.5 \mathrm{~L} \mathrm{~min} \nabla^{1}\right)$, nebulizer gas flow $(0.7 \mathrm{~L}$ $\left.\min \otimes^{1}\right)$, and sample introduction flow rate $\left(2.1 \mathrm{~mL} \min \otimes^{1}\right)$. The emission lines monitored were $\mathrm{Sb} 206.8$ and $231.1 \mathrm{~nm}$.

\subsection{Multivariate optimization of adsorption procedure}

A full factorial design $\left(2^{4}\right)$ was used in order optimize experimental conditions of adsorption procedure for $\mathrm{Sb}$ removal from wastewater. In this study, the variables were evaluated in three levels including the central point: (i) pH solution (2, 6, and 10), (ii) adsorption time (5, 60, and $115 \mathrm{~min})$, (iii) concentration of the $\mathrm{Sb}$ standard $\left(2.0,5.0\right.$, and $\left.8.0 \mathrm{mg} \mathrm{L}^{-1}\right)$, and (iv) adsorbent mass $(5,25$, and $45 \mathrm{mg})$. A total of 19 experiments were carried including triplicate in the central point, that was used to estimate the pure error. As response to full factorial design $\left(2^{4}\right)$ was calculated (\%) removal of Sb, obtained from Eq. (1):

$$
\% \text { removal of } S b=\frac{\left(\text { Concentration }_{\text {added }}-\text { Concentration }_{\text {found }}\right)}{\text { Concentration }_{\text {added }}} \times 100
$$

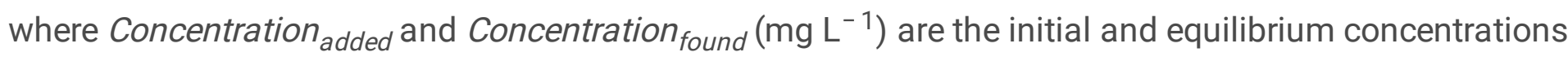
of Sb, respectively.

Adsorption experiments were conducted in amber flasks $\left(25^{\circ} \mathrm{C}, 400 \mathrm{rpm}\right)$ in $5 \mathrm{~mL}$ of Sb solution. After adsorption process, the samples were centrifuged (3500 rpm, $5 \mathrm{~min})$, and then the supernatant concentration was performed using an ICP OES. 


\section{Results And Discussion}

As mentioned before, all characterizations of the $\mathrm{RH}$ and $\mathrm{RHA}$ were performed in our recently published article in the literature (Costa and Paranhos 2018), however this characterization was complemented by SEM/EDS analysis.

\subsection{Characterization of MCM-48 (RHA) adsorbent}

Figure 1(a) illustrates the FTIR spectra obtained for the MCM-48 (RHA) mesoporous array before and after the CTAB removal. The MCM-48 (RHA) with CTAB presents the narrow bands centered around at 2921 , 2852, and $1485 \mathrm{~cm}^{-1}$ referents to the $\mathrm{C}-\mathrm{H}$ stretch of the $\mathrm{CH}_{2}$ and $\mathrm{CH}_{3}$ groups of the CTAB groups. However these bands are absent in the calcined MCM-48 (RHA) (Santos et al. 2019). It is also possible to observe for both samples, a broad band around at $3443 \mathrm{~cm}^{-1}$, which can be attributed to the vibration of the $\mathrm{O}-\mathrm{H}$ bond of the $\mathrm{Si}-\mathrm{OH}$ groups, as well as the vibration related to the stretching of the $\mathrm{O}-\mathrm{H}$ bond of $\mathrm{H}-\mathrm{O}-\mathrm{H}$ molecules adsorbed on the surface of the MCM-48 (RHA) (Jang et al. 2009), and also a narrow band around at $1634 \mathrm{~cm}^{-1}$ that is assigned to the flexion vibration of $\mathrm{H}_{2} \mathrm{O}$ molecules trapped within the mesoporous matrix of the MCM-48 (RHA). Finally, it is possible to observe the main bands associated with the cubic structure of the MCM-48 (RHA), confirmed by the bands located around at $1089 \mathrm{~cm}^{-1}\left(v_{a s}\right.$, $\mathrm{Si}-0-\mathrm{Si}) ; 965 \mathrm{~cm}^{-1}\left(v_{S}, \mathrm{Si}-\mathrm{OH}\right) ; 806 \mathrm{~cm}^{-1}\left(v_{S} \mathrm{Si}-0\right)$, and at $465 \mathrm{~cm}^{-1}(\delta, \mathrm{Si}-\mathrm{O}-\mathrm{Si})$ (Endud and Wong 2007; Jang et al. 2009).

Although the MCM-48 (RHA) mesoporous matrix presents a high degree of ordering from the small angle $\mathrm{XRD}$ analysis, it is typical that mesoporous materials also have an amorphous diffraction pattern, as seen from the high angle XRD analysis (Fig. 1(b), which can be attributed to the amorphous condensed silica framework of MCM-48 (RHA) array from the silica source used in its hydrothermal synthesis (Costa et al. 2020d).

Figure 1(c) shows the results of the liquid $\mathrm{N}_{2}$ adsorption/desorption analysis for MCM-48 (RHA). It is possible to observe that the $\mathrm{N}_{2}$ adsorption/desorption isotherms present a characteristic profile of type IV isotherm and type $\mathrm{H} 1$ hysteresis with high adsorption of liquid $\mathrm{N}_{2}$, according to the IUPAC classification for nanostructured materials of the M41S family of mesoporous materials (Santos et al. 2019; Costa et al. $2020 d, c)$. Furthermore, these results are confirmed by the narrow mesopores distribution shown by MCM-48 (RHA), which is a characteristic profile of mesoporous matrixes with well-defined regular arrays of mesopores and high $\mathrm{N}_{2}$ adsorption values. The textural and structural features of MCM-48 (RHA) mesoporous array were calculated from the $\mathrm{N}_{2}$ adsorption and desorption isotherms, which were summarized in Table 1. In summary, the MCM-48 (RHA) mesoporous material showed: (i) high surface area $\left(S_{B E T}\right)$ value, calculated from BET method; (ii) high pore volume $(V)$ and total pore volume $\left(V_{T}\right)$ values; and (iii) average pore diameter and pore diameter $\left(D_{B J H}\right)$ values between the range of mesoporous materials, which were defined between 2 and $50 \mathrm{~nm}$. The high degree of ordering of the cubic mesoporous structure of MCM-48 has been demonstrated previously (Santos et al. 2019) from the small 
angle XRD analysis, which presented the main diffraction planes (211 and 220) of la3d space-group symmetry.

Table 1

Textural and structural properties of MCM-48 (RHA) mesoporous material

\begin{tabular}{|c|c|c|c|c|c|}
\hline Sample & $\begin{array}{l}S_{\mathrm{BET}} \\
\left(\mathrm{m}^{2} \mathrm{~g}^{-1}\right)\end{array}$ & $\begin{array}{l}V \\
\left(\mathrm{~cm}^{3} \mathrm{~g}^{-1}\right)\end{array}$ & $\begin{array}{l}V_{\mathrm{T}} \\
\left(\mathrm{cm}^{3} \mathrm{~g}^{-1}\right)\end{array}$ & $\begin{array}{l}D_{\mathrm{BJH}} \\
(\mathrm{nm})\end{array}$ & Average pore Diameter \\
\hline MCM-48 (RHA) & 820.94 & 0.18 & 0.55 & 3.66 & 2.69 \\
\hline
\end{tabular}

The SEM images obtained for untreated and treated RH and RHA, as well as for the MCM-48 (RHA) are shown in Fig. 2a(i-iii). The untreated RH showed an external epidermis, which is well-organized and has a rippled surface with an elongated and contorted shape, as well as the appearance of a corn cob. However, after the acid treatment carried out therein (Fig. 2a(ii), it is possible to observe that the surface of the RH has become more rough, due to the dilution or destruction of the amorphous region of the fibers present in the rice husk (Johara et al. 2012; Costa and Paranhos 2018). Thus, the external epidermis of the RHA, presents the same characteristic of the raw $\mathrm{RH}$, however, in the external epidermis it concentrates the greater percentage of silica (Della et al. 2002, 2005). Therefore, Fig. 2a(iii) shows the internal epidermis of the RHA, which shows the porous structure known as the silica skeleton, from the burning of the organic matter of the RH fibers, and this region also contains a considerable amount of silica (Liou 2004; Ahmed and Adam 2007).

The morphology of the MCM-48 (RHA) mesoporous material was evaluated by SEM, as shown in the image presented in Fig. 2a(iv). Thus, it is possible to observe that the MCM-48 (RHA) presented an agglomerate of uniform spherical particles from the amorphous silica matrix, which is characteristic of the nanostructured mesoporous architecture of the M41S family (Costa et al. 2015). From the SEM-EDS analysis it was possible to determine the chemical composition of the MCM-48 (RHA) (Fig. 2b). The MCM-48 (RHA) presented a high content of $\mathrm{Si}$ and $\mathrm{O}$, as these are the main constituents of the framework of the amorphous material responsible for the formation of the MCM-48 (RHA) mesoporous material.

\subsection{Multivariate optimization of adsorption procedure}

Usually, the adsorption procedures are carried using univariate methodology, which requires a high number of experiments, and consequently greater waste generation and higher cost. To get around these problems, a factorial design was used to optimize the variables involved in adsorption procedures. Table 2 shows a matrix experimental for the full factorial design $\left(2^{4}\right)$ containing 19 experiments with real and coded values and the response in function of the \% removal of $\mathrm{Sb}$. Before of evaluating the best conditions for the \% removal of $\mathrm{Sb}$, it was necessary to evaluate the quality of the linear model obtained from the factorial design. To evaluate check the quality of the linear model, an analysis of variance (ANOVA) was performed, and the results are available in Table 3. 
Table 2

Matrix of the full factorial design $\left(2^{4}\right)$ with real and coded values and the response in function of the \% removal of $\mathrm{Sb}$

\begin{tabular}{|c|c|c|c|c|c|}
\hline \multirow{3}{*}{ Experiment } & \multicolumn{5}{|c|}{ Variables } \\
\hline & $\mathrm{pH}$ & $\begin{array}{l}\text { Adsorption } \\
\text { time }\end{array}$ & $\begin{array}{l}\text { Concentration of Sb } \\
\text { standard }\end{array}$ & $\begin{array}{l}\text { Adsorbent } \\
\text { mass }\end{array}$ & $\begin{array}{l}\% \text { Sb } \\
\text { removal }\end{array}$ \\
\hline & & $(\min )$ & $\left(\mathrm{mol} \mathrm{L}^{\circledR 1}\right)$ & (mg) & \\
\hline 1 & $\begin{array}{l}2 \\
(-1)\end{array}$ & $5(-1)$ & $2(-1)$ & $5(-1)$ & 24 \\
\hline 2 & $\begin{array}{l}10 \\
(1)\end{array}$ & $5(-1)$ & $2(-1)$ & $5(-1)$ & 60 \\
\hline 3 & $\begin{array}{l}2 \\
(-1)\end{array}$ & $115(1)$ & $2(-1)$ & $5(-1)$ & 74 \\
\hline 4 & $\begin{array}{l}10 \\
(1)\end{array}$ & $115(1)$ & $2(-1)$ & $5(-1)$ & 85 \\
\hline 5 & $\begin{array}{l}2 \\
(-1)\end{array}$ & $5(-1)$ & $8(1)$ & $5(-1)$ & 55 \\
\hline 6 & $\begin{array}{l}10 \\
(1)\end{array}$ & $5(-1)$ & $8(1)$ & $5(-1)$ & 76 \\
\hline 7 & $\begin{array}{l}2 \\
(-1)\end{array}$ & $115(1)$ & $8(1)$ & $5(-1)$ & 74 \\
\hline 8 & $\begin{array}{l}10 \\
(1)\end{array}$ & $115(1)$ & $8(1)$ & $5(-1)$ & 82 \\
\hline 9 & $\begin{array}{l}2 \\
(-1)\end{array}$ & $5(-1)$ & $2(-1)$ & $45(1)$ & 80 \\
\hline 10 & $\begin{array}{l}10 \\
(1)\end{array}$ & $5(-1)$ & $2(-1)$ & $45(1)$ & 84 \\
\hline 11 & $\begin{array}{l}2 \\
(-1)\end{array}$ & $115(1)$ & $2(-1)$ & $45(1)$ & 89 \\
\hline 12 & $\begin{array}{l}10 \\
(1)\end{array}$ & $115(1)$ & $2(-1)$ & $45(1)$ & 89 \\
\hline 13 & $\begin{array}{l}2 \\
(-1)\end{array}$ & $5(-1)$ & $8(1)$ & $45(1)$ & 92 \\
\hline 14 & $\begin{array}{l}10 \\
(1)\end{array}$ & $5(-1)$ & $8(1)$ & $45(1)$ & 94 \\
\hline 15 & $\begin{array}{l}2 \\
(-1)\end{array}$ & $115(1)$ & $8(1)$ & $45(1)$ & 95 \\
\hline
\end{tabular}




\begin{tabular}{|llllll|}
\hline \multicolumn{7}{|l|}{ Variables } \\
\hline 16 & 10 & $115(1)$ & $8(1)$ & $45(1)$ & 94 \\
\hline $17(C P)$ & $6(0)$ & $60(0)$ & $5(0)$ & $25(0)$ & 93 \\
\hline $18(C P)$ & $6(0)$ & $60(0)$ & $5(0)$ & $25(0)$ & 93 \\
\hline $19(C P)$ & $6(0)$ & $60(0)$ & $5(0)$ & $25(0)$ & 93 \\
\hline
\end{tabular}

CP. central point.

Table 3. ANOVA table in function in function of the $\%$ removal of Sb with a $95 \%$ confidence level

\begin{tabular}{|c|c|c|c|c|c|}
\hline Parameters & $S S$ & d.f & $M S$ & $F_{\text {calculated }}$ & $F_{\text {tabulated }}$ \\
\hline Regression & 5102 & 4 & 1275 & 51.80 & 3.111 \\
\hline Residual & 57.25 & 14 & 4.089 & & \\
\hline Lack of fit & 49.25 & 2 & 24.62 & 6.156 & 19.00 \\
\hline Pure error & 8.000 & 2 & 4.000 & & \\
\hline Total & 5159 & 18 & & & \\
\hline
\end{tabular}

SS. sum of square; $\boldsymbol{d . f}$. degree of freedom; $\boldsymbol{M S}$. mean of square.

To evaluate a model the first step and check the significance of regression. For that it must be a comparison between the ratio of Mean Square of Regression $\left(\mathrm{MS}_{\mathrm{R}}\right)$ and Mean Square of Residue $\left(\mathrm{M}_{\mathrm{Sr}}\right)$ was performed. In this case, the F_calculated (51.80) was 17-fold higher than the F_tabulated (3.111) at the $95 \%$ confidence level. These data demonstrate that the regression of the model is highly significant, which gives credibility to the linear model. The second step for the evaluation of model and check if there is lack of fit. In the case, a comparison between the ratio of Mean square of lack of fit $\left(\mathrm{MS}_{\text {lof }}\right)$ and Mean Square of pure error $\left(\mathrm{MS}_{\mathrm{pe}}\right)$ was performed. It was observed that the model does not presented lack of fit because the F_calculated (6.156) was lower than the value of F_tabulated (19.00) at the 95\% confidence level. In addition, the quality of the linear model also was evaluated by analyzing the graphic of predicted values versus observed, as shown in Fig. 3. Thus, it is possible to observe that the model is well adjusted with $99 \%$ regression percentage. This observation confirms the good fit of the model that was verified in the Table 3.

After data processing, the evaluation of best conditions for adsorption procedure for the \% $\mathrm{Sb}$ removal was performed by analysis of Pareto graphic (Fig. 4), evaluating the significance of the variables and their interactions, at a confidence level of 95\% (Ferreira et al. 2018). According to the results presented in Fig. 4 (Pareto graphic), the first order variables are all significant. In addition, some second and third order interactions are also significant. The discussion of the influence of variables on the \% removal of Sb will 
follow the order of significance presented in the Pareto graphic, according to the following sequence: (i) adsorbent mass; (ii) adsorption time; (iii) pH solution; and (iv) concentration of the Sb standard.

The adsorbent mass is the most important variable, and the adsorption efficiency increases with the increase in the mass of the MCM-48 (RHA) adsorbent material. Removal efficiency of Sb can be related to the increased surface area of mesoporous array, well as the availability of more adsorption sites for Sb within the framework of architectured matrix of MCM-48 (RHA) (Costa and Paranhos 2020; Costa et al. 2020b). Thus, to ensure a high removal percentage of $\mathrm{Sb}$, we choose to use a mass of $45 \mathrm{mg}$.

The adsorption time is an important variable, especially when new adsorbents are tested (Costa and Paranhos 2019; Costa et al. 2020a, c). In this study, the adsorption time showed a positive effect on the removal efficiency of Sb by MCM-48 (RHA) adsorbent. We verified from Table 2, that the adsorption times evaluated showed excellent results, especially when combined with the condition of greater mass of adsorbent was used. This behavior can be seen between experiments 9 to 19 as shown in Table 2 . Figure 4 also shows that the interaction between adsorbent mass and adsorption time is significant with a negative effect, that is, one of the variables must be tested at the maximum level and the other at the lower level. As the adsorbent mass has been fixed at the maximum level $(45 \mathrm{mg})$, the adsorption time can be fixed using the condition of the central point (60 min).

The $\mathrm{pH}$ solution is an important factor affecting the removal of the metal species in aqueous solution. The dependence on metal adsorption in function of the $\mathrm{pH}$ solution is related to the type of metal that is in the solution, and to the state of ionization of the adsorbent functional group, which affects the availability of the binding sites. Under the established conditions, the experiments were carried at $\mathrm{pH}$ solution ranging from 2 to 10, as shown in Table 2. Under the established conditions, the experiments were carried at $\mathrm{pH}$ ranging from 2 to 10 . It is possible to observe in Table 2 that the removal percentage was adequate in the $\mathrm{pH}$ range evaluated, except in experiments $1,2,3,5,6$ and 7 , which showed removal efficiency below $80 \%$. However, it is possible to verify that in the mentioned experiments, the adsorbent mass tested was $5 \mathrm{mg}$, which seems to interfere in the $\mathrm{Sb}$ removal in function of the tested $\mathrm{pH}$ range. In the experiments that were used mass of 25 and $45 \mathrm{mg}$, the removal percentage stayed above $85 \%$. These observations show that the studied material has a good adsorption capacity in the $\mathrm{Sb}$ remediation in solutions with $\mathrm{pH}$ ( 2 to 10 ) using the mass greater than $25 \mathrm{mg}$. As the purpose of the applying MCM-48based mesoporous array is to remove $\mathrm{Sb}$ from different water samples, we understand that there is no need to establish an optimal $\mathrm{pH}$ condition. In this case, we can establish a pH range between 2 and 10 using an adsorbent mass of $45 \mathrm{mg}$. The no need of $\mathrm{pH}$ adjustment is interesting and increases the frequency of the analytical method proposed. In this study, the variable concentration of the Sb standard showed a positive effect. This behavior is very interesting because it shows that adsorbent has the capacity to remove concentrations of $\mathrm{Sb}$ considered high.

Figure 5 shows the graph of the desirability to the variables evaluated with the most appropriate condition marked with a red line. Thus, the established conditions were: adsorbent mass ( $45 \mathrm{mg}$ ); adsorption time (60 min); $\mathrm{pH}$ (ranged from 2 to 10 ); and concentration of the Sb standard (8 mol L $\mathbb{\bigotimes}^{1}$ ). 


\subsection{Application using real samples}

The proposed method of adsorption was applied for the $\mathrm{Sb}$ removal in samples of environmental interest, in the case of this study in water samples. Commonly, the concentration of $\mathrm{Sb}$ in water samples is at a trace level ( $\mathrm{ppb}$ ), in this sense the samples analyzed were enriched with known concentrations of $\mathrm{Sb}$. A total of five samples were analyzed and Sb concentrations on the order of $8 \mathrm{ppm}$ were added. These samples were submitted to the adsorption procedure with the optimized conditions, and subsequently the final aqueous solution was subjected to analysis by ICP OES. From Eq. 1 it was possible to calculate the $\%$ removal of Sb which varied from 88 to $96 \%$. The adsorbent proposed had not matrix effect in the adsorption process, and thus confirming that can be used in the remediation of $\mathrm{Sb}$ in water samples.

\section{Conclusions}

In this present approach, we carry out the synthesis of MCM-48-based mesoporous array via an inexpensive, sustainable, and eco-friendly hydrothermal method using an alternative silica source extracted from the rice husk ash. The prepared mesoporous material was subsequently tested as an adsorbent material in the $\mathrm{Sb}$ remediation, which was completely useful in the adsorption of this metal.

The prepared MCM-48 (RHA) array exhibited an amorphous framework with the $\mathrm{N}_{2}$ adsorption/desorption isotherms of type IV and type $\mathrm{H} 1$ hysteresis, due to the high nitrogen adsorption, surface area, and pore volume, and average pore diameter between the range of mesoporous materials. In addition, the mesoporous matrix presents a narrow mesopores distribution and uniform spherical particles, typical the architectures with well-defined regular channels. In addition, the variables of adsorption procedure were optimized using a full factorial design $\left(2^{4}\right)$. In this case, the factorial design was useful to find the optimized conditions using a smaller number of experiments. We also highlight the effectiveness of the MCM-48, which does not need to adjust the $\mathrm{pH}$ of aqueous solutions, this increases the analytical frequency method proposed.

\section{Declarations}

\section{Compliance with ethical standards}

\section{Ethics approval}

Not applicable.

\section{Consent to participate}

Not applicable.

\section{Consent for publication}

The Authors transfer to Springer the publication rights. 
Availability of data and materials

The authors declare that data supporting the findings of this study are available within the article.

\section{Competing interests}

The authors declare that they have no known competing financial interests or personal relationships that could have appeared to influence the work reported in this paper.

\section{Funding}

The authors wish to thank Fundação de Amparo à Pesquisa do Estado de São Paulo (FAPESP) and Centro de Desenvolvimento de Materiais Funcionais for providing the essential financial support.

\section{Authors' contributions}

José Arnaldo Santana Costa: Conceptualization, Methodology, Validation, Investigation, Formal analysis, Resources, Writing - Original Draft. Vinicius Câmara Costa: Conceptualization, Methodology, Validation, Investigation, Formal analysis, Resources, Writing - Original Draft. Matheus Lima de Mello: Methodology, Validation, Formal analysis. Caio Marcio Paranhos: Conceptualization, Methodology, Validation, Investigation, Formal analysis, Resources, Writing - Original Draft, Supervision.

\section{Acknowledgments}

The authors thank Fundação de Amparo à Pesquisa do Estado de São Paulo (FAPESP) (Grant 2017/06775-5) and Centro de Desenvolvimento de Materiais Funcionais (CDMF) (Grant 2013/07296-2) for the financial support.

\section{References}

1. Ahmed AE, Adam F (2007) Indium incorporated silica from rice husk and its catalytic activity. Microporous Mesoporous Mater 103:284-295. doi:10.1016/j.micromeso.2007.01.055

2. Akhil D, Lakshmi D, Senthil Kumar $P$ et al (2021) Occurrence and removal of antibiotics from industrial wastewater. Environ Chem Lett 19:1477-1507. doi:10.1007/s10311-020-01152-0

3. Ambursa MM, Sudarsanam P, Voon LH et al (2017) Bimetallic Cu-Ni catalysts supported on MCM-41 and Ti-MCM-41 porous materials for hydrodeoxygenation of lignin model compound into transportation fuels. Fuel Process Technol 162:87-97. doi: 10.1016/J.FUPROC.2017.03.008

4. Antoniadis V, Golia EE, Liu Y-T et al (2019) Soil and maize contamination by trace elements and associated health risk assessment in the industrial area of Volos, Greece. Environ Int 124:79-88. doi:10.1016/j.envint.2018.12.053

5. Aquino FWB, Paranhos CM, Pereira-Filho ER (2016) Method for the production of acrylonitrilebutadiene-styrene (ABS) and polycarbonate (PC)/ABS standards for direct Sb determination in 
plastics from e-waste using laser-induced breakdown spectroscopy. J Anal At Spectrom 31:12281233. doi:10.1039/C6JA00038J

6. Arumugam A, Karuppasamy G, Jegadeesan GB (2018) Synthesis of mesoporous materials from bamboo leaf ash and catalytic properties of immobilized lipase for hydrolysis of rubber seed oil. Mater Lett 225:113-116. doi:10.1016/J.MATLET.2018.04.122

7. Castillo X, Pizarro J, Ortiz C et al (2018) A cheap mesoporous silica from fly ash as an outstanding adsorbent for sulfate in water. Microporous Mesoporous Mater 272:184-192. doi:10.1016/J.MICROMESO.2018.06.014

8. Chen Z, Zhang S, Liu Y et al (2020) Synthesis and fabrication of g-C3N4-based materials and their application in elimination of pollutants. Sci Total Environ 731:139054.

doi:10.1016/j.scitotenv.2020.139054

9. Chu J, Mao J, He M (2019) Anthropogenic antimony flow analysis and evaluation in China. Sci Total Environ 683:659-667. doi:10.1016/j.scitotenv.2019.05.293

10. Costa JAS, Costa VC, Pereira-Filho ER, Paranhos CM (2020a) Removal of Cr(VI) from Wastewater of the Tannery Industry by Functionalized Mesoporous Material. Silicon 12:1895-1903. doi:10.1007/s12633-019-00315-1

11. Costa JAS, de Jesus RA, da Silva CMP, Romão LPC (2017a) Efficient adsorption of a mixture of polycyclic aromatic hydrocarbons (PAHs) by $\mathrm{Si}-\mathrm{MCM}-41$ mesoporous molecular sieve. Powder Technol 308:434-441. doi:10.1016/j.powtec.2016.12.035

12. Costa JAS, de Jesus RA, Dorst DD et al (2017b) Photoluminescent properties of the europium and terbium complexes covalently bonded to functionalized mesoporous material PABA-MCM-41. J Lumin 192:1149-1156. doi:10.1016/j.jlumin.2017.08.046

13. Costa JAS, de Jesus RA, Santos DO et al (2020b) Recent progresses in the adsorption of organic, inorganic, and gas compounds by MCM-41-based mesoporous materials. Microporous Mesoporous Mater 291:109698. doi:10.1016/j.micromeso.2019.109698

14. Costa JAS, de Jesus RA, Santos DO et al (2021a) Synthesis, functionalization, and environmental application of silica-based mesoporous materials of the M41S and SBA-n families: A review. J Environ Chem Eng 9:105259. doi:10.1016/j.jece.2021.105259

15. Costa JAS, Garcia ACFS, Santos DO et al (2015) Applications of inorganic-organic mesoporous materials constructed by self-assembly processes for removal of benzo[k]fluoranthene and benzo[b]fluoranthene. J Sol-Gel Sci Technol 75:495-507. doi:10.1007/s10971-015-3720-6

16. Costa JAS, Garcia ACFS, Santos DO et al (2014) A new functionalized MCM-41 mesoporous material for use in environmental applications. J Braz Chem Soc 25:197-207. doi:10.5935/01035053.20130284

17. Costa JAS, Paranhos CM (2020) Mitigation of silica-rich wastes: An alternative to the synthesis ecofriendly silica-based mesoporous materials. Microporous Mesoporous Mater 309:110570. doi:10.1016/j.micromeso.2020.110570 
18. Costa JAS, Paranhos CM (2019) Evaluation of rice husk ash in adsorption of Remazol Red dye from aqueous media. SN Appl Sci 1:397. doi:10.1007/s42452-019-0436-1

19. Costa JAS, Paranhos CM (2018) Systematic evaluation of amorphous silica production from rice husk ashes. J Clean Prod 192:688-697. doi:10.1016/j.jclepro.2018.05.028

20. Costa JAS, Sarmento VHV, Romão LPC, Paranhos CM (2021b) Polycyclic Aromatic Hydrocarbons Removal from Aqueous Solution with PABA-MCM-41/Polyethersulfone Mixed Matrix Membranes. Silicon. doi:10.1007/s12633-021-01165-6

21. Costa JAS, Sarmento VHV, Romão LPC, Paranhos CM (2020c) Performance of the MCM-41-NH2 Functionalized Mesoporous Material Synthetized from the Rice Husk Ash on the Removal of the Polycyclic Aromatic Hydrocarbons. Silicon 12:1913-1923. doi:10.1007/s12633-019-00289-0

22. Costa JAS, Sarmento VHV, Romão LPC, Paranhos CM (2020d) Removal of polycyclic aromatic hydrocarbons from aqueous media with polysulfone/MCM-41 mixed matrix membranes. J Memb Sci 601:117912. doi:10.1016/j.memsci.2020.117912

23. Costa VC, de Babos DV, de Aquino FWB et al (2018) Direct Determination of Ca, $\mathrm{K}$ and $\mathrm{Mg}$ in Cassava Flour Samples by Laser-Induced Breakdown Spectroscopy (LIBS). Food Anal Methods 11:18861896. doi:10.1007/s12161-017-1086-9

24. Costa VC, Pinheiro FC, Amorim FAC et al (2019) Multivariate optimization for the development of a sample preparation procedure and evaluation of calibration strategies for nutrient elements determination in handmade chocolate. Microchem J 150:104166. doi:10.1016/j.microc.2019.104166

25. de Sá IP, Higuera JM, Costa VC et al (2020) Determination of Trace Elements in Meat and Fish Samples by MIP OES Using Solid-Phase Extraction. Food Anal Methods 13:238-248. doi:10.1007/s12161-019-01615-3

26. Della V, Kuhn I, Hotza D (2002) Rice husk ash as an elemente source for active silicaproduction. Mater Lett 57:818-821. doi:10.1016/S0167-577X(02)00879-0

27. Della VP, Kühn I, Hotza D (2005) Reciclagem de Resíduos Agro-Industriais: Cinza de Casca de Arroz como Fonte Alternativa de Sílica. Cerâmica Ind 10:22-25

28. Endud S, Wong KL (2007) Mesoporous silica MCM-48 molecular sieve modified with SnCl2in alkaline medium for selective oxidation of alcohol. Microporous Mesoporous Mater 101:256-263. doi:10.1016/j.micromeso.2006.12.029

29. Ferreira SLC, Caires AO, Borges T da S, et al (2017) Robustness evaluation in analytical methods optimized using experimental designs. Microchem J 131:163-169. doi:10.1016/j.microc.2016.12.004

30. Ferreira SLC, Lemos VA, de Carvalho VS et al (2018) Multivariate optimization techniques in analytical chemistry - an overview. Microchem J 140:176-182. doi:10.1016/j.microc.2018.04.002

31. Gamela RR, Costa VC, Pereira-Filho ER (2020) Multivariate Optimization of Ultrasound-Assisted Extraction Procedure for the Determination of $\mathrm{Ca}, \mathrm{Fe} \mathrm{K}, \mathrm{Mg}, \mathrm{Mn}, \mathrm{P}$, and $\mathrm{Zn}$ in Pepper Samples by ICP OES. Food Anal Methods 13:69-77. doi: 10.1007/s12161-019-01524-5 
32. Ghorbani F, Younesi H, Mehraban Z et al (2013) Preparation and characterization of highly pure silica from sedge as agricultural waste and its utilization in the synthesis of mesoporous silica MCM-41. J Taiwan Inst Chem Eng 44:821-828. doi:10.1016/j.jtice.2013.01.019

33. Jang HT, Park YK, Ko YS et al (2009) Highly siliceous MCM-48 from rice husk ash for CO2 adsorption. Int J Greenh Gas Control 3:545-549. doi:10.1016/j.ijggc.2009.02.008

34. Johara N, Ahmada I, Dufresne A (2012) Extraction, preparation and characterization of cellulose fibres and nanocrystals from rice husk. Ind Crops Prod 37:93-99. doi:10.1016/j.indcrop.2011.12.016

35. Li X, Dong L, Zhang J et al (2019) In-situ catalytic upgrading of biomass-derived vapors using HZSM5 and MCM-41: Effects of mixing ratios on bio-oil preparation. J Energy Inst 92:136-143. doi:10.1016/J.JOEI.2017.10.015

36. Liou TH (2004) Preparation and characterization of nano-structured silica from rice husk. Mater Sci Eng A 364:313-323. doi:10.1016/j.msea.2003.08.045

37. Ma Y, Chen H, Shi Y, Yuan S (2016) Low cost synthesis of mesoporous molecular sieve MCM-41 from wheat straw ash using CTAB as surfactant. Mater Res Bull 77:258-264. doi:10.1016/J.MATERRESBULL.2016.01.052

38. Meng L, Wu M, Chen $\mathrm{H}$ et al (2020) Rejection of antimony in dyeing and printing wastewater by forward osmosis. Sci Total Environ 745:141015. doi:10.1016/j.scitotenv.2020.141015

39. Norsuraya S, Fazlena H, Norhasyimi R (2016) Sugarcane Bagasse as a Renewable Source of Silica to Synthesize Santa Barbara Amorphous-15 (SBA-15). Procedia Eng 148:839-846. doi:10.1016/J.PROENG.2016.06.627

40. Santos LFS, de Jesus RA, Costa JAS et al (2019) Evaluation of MCM-41 and MCM-48 mesoporous materials as sorbents in matrix solid phase dispersion method for the determination of pesticides in soursop fruit (Annona muricata). Inorg Chem Commun 101:45-51.

doi:10.1016/j.inoche.2019.01.013

41. Sohrabnezhad S, Daraie Mooshangaie S (2019) In situ fabrication of n-type Ag/AgBr nanoparticles in MCM-41 with rice husk (RH/MCM-41) composite for the removal of Eriochrome Black-T. Mater Sci Eng B 240:16-22. doi:10.1016/J.MSEB.2019.01.007

42. Viczek SA, Aldrian A, Pomberger R, Sarc R (2020) Origins and carriers of Sb, As, Cd, Cl, Cr, Co, Pb, Hg, and $\mathrm{Ni}$ in mixed solid waste - A literature-based evaluation. Waste Manag 103:87-112. doi:10.1016/j.wasman.2019.12.009

43. Xiang-Xue W, Xing L, Jia-Qi W, Hong-Tao Z (2019) Recent Advances in Carbon Nitride-Based Nanomaterials for the Removal of Heavy Metal Ions from Aqueous Solution. J Inorg Mater 436. doi:10.15541/jim20190436

44. Xu D, Gao B, Peng W et al (2019) Geochemical and health risk assessments of antimony (Sb) in sediments of the Three Gorges Reservoir in China. Sci Total Environ 660:1433-1440. doi:10.1016/j.scitotenv.2019.01.014

45. Zhao Z, Wang X, Zhao $C$ et al (2010) Adsorption and desorption of antimony acetate on sodium montmorillonite. J Colloid Interface Sci 345:154-159. doi:10.1016/j.jcis.2010.01.054 
Figures
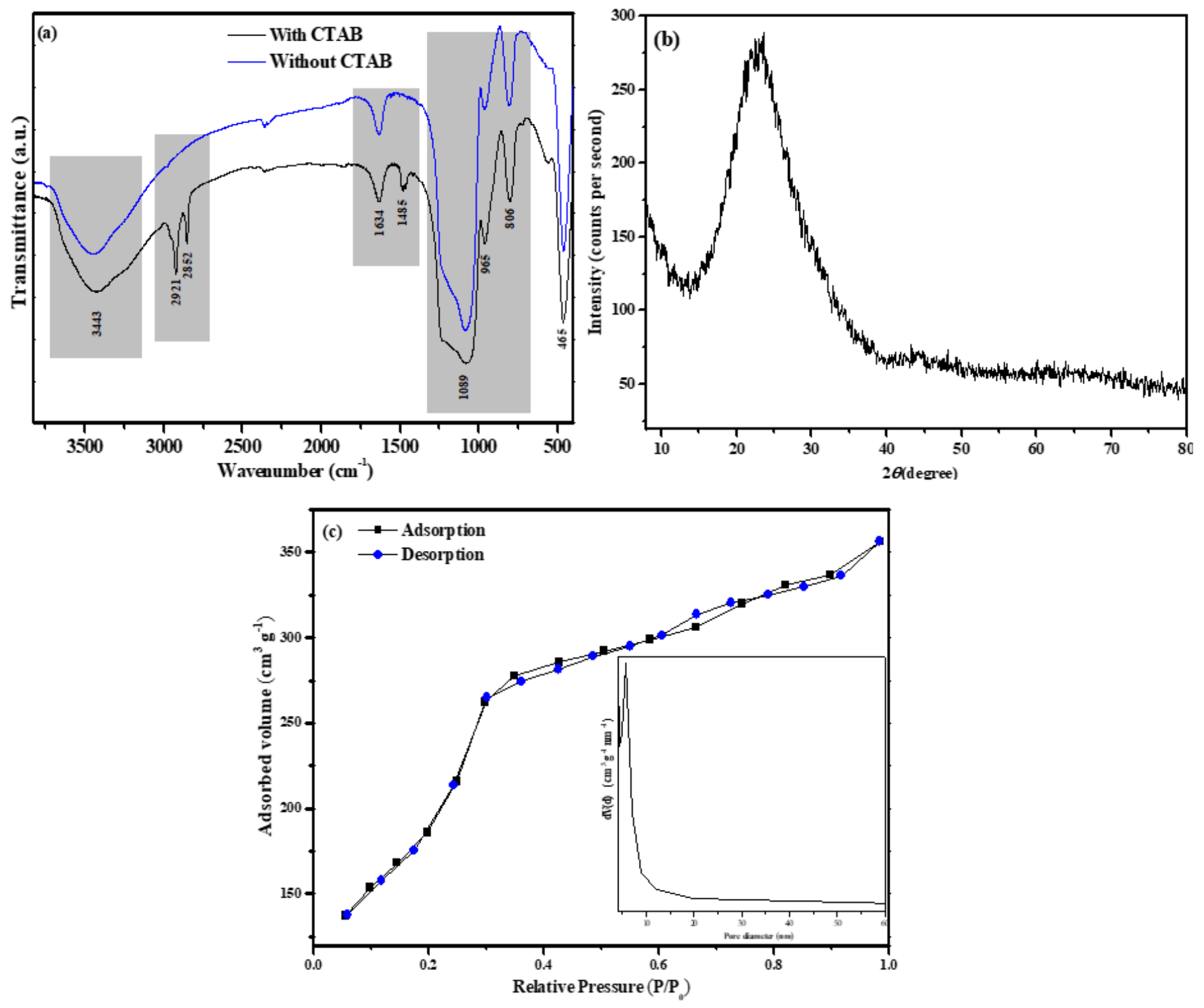

Figure 1

FTIR spectra of MCM-48 (RHA) mesoporous array before and after CTAB removal (a), XRD profile (b), and $\mathrm{N} 2$ adsorption/desorption isotherms and BJH pore size distribution of MCM-48 (RHA) mesoporous material without CTAB surfactant (c). 
(a)
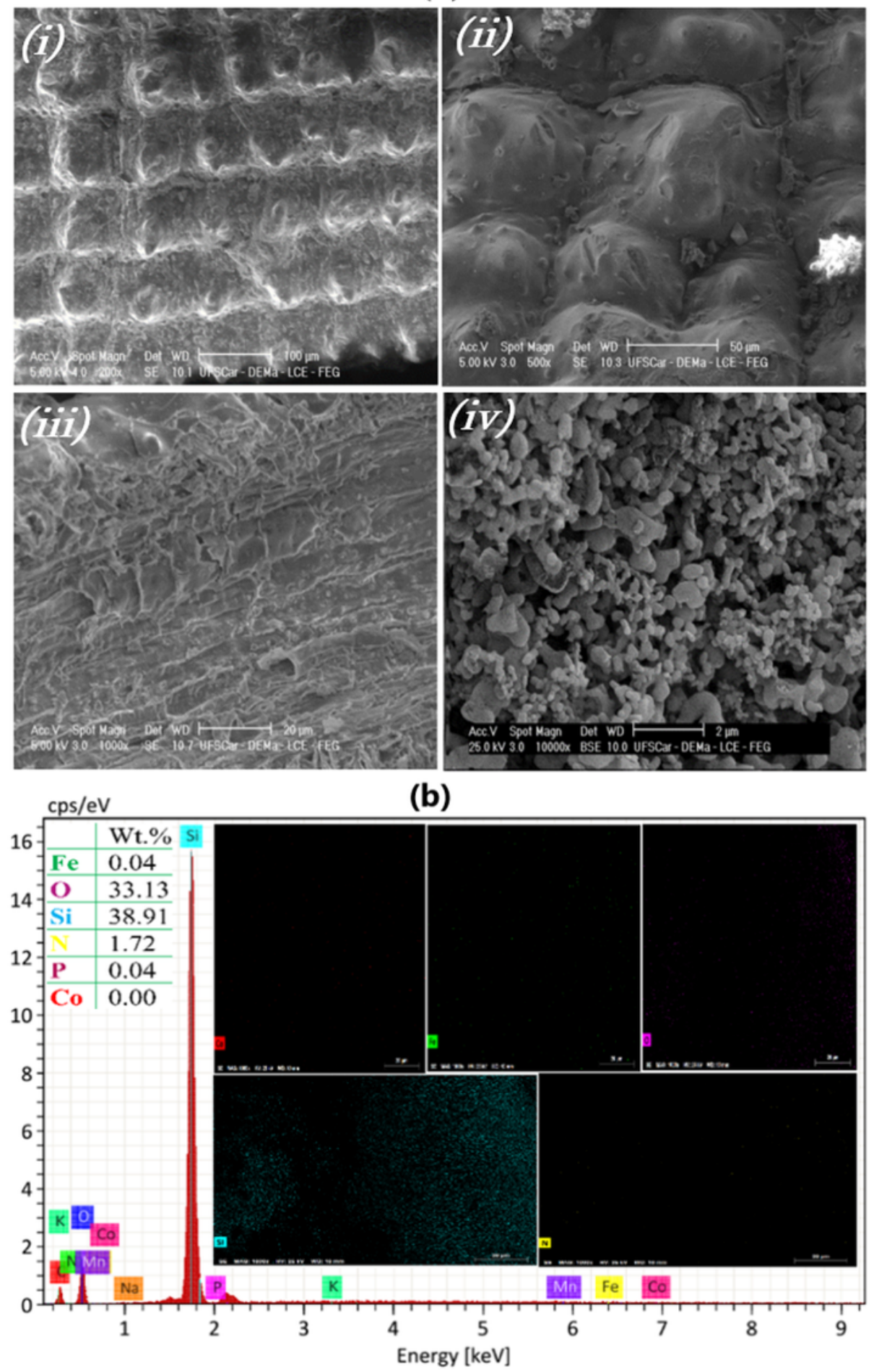

\section{Figure 2}

MEV of (i) untreated and (ii) treated RH, (iii) treated RHA, and (iv) MCM-48 (RHA) mesoporous array (a) and EDS spectrograph and elemental mapping of MCM-48 (RHA) mesoporous material (b). 


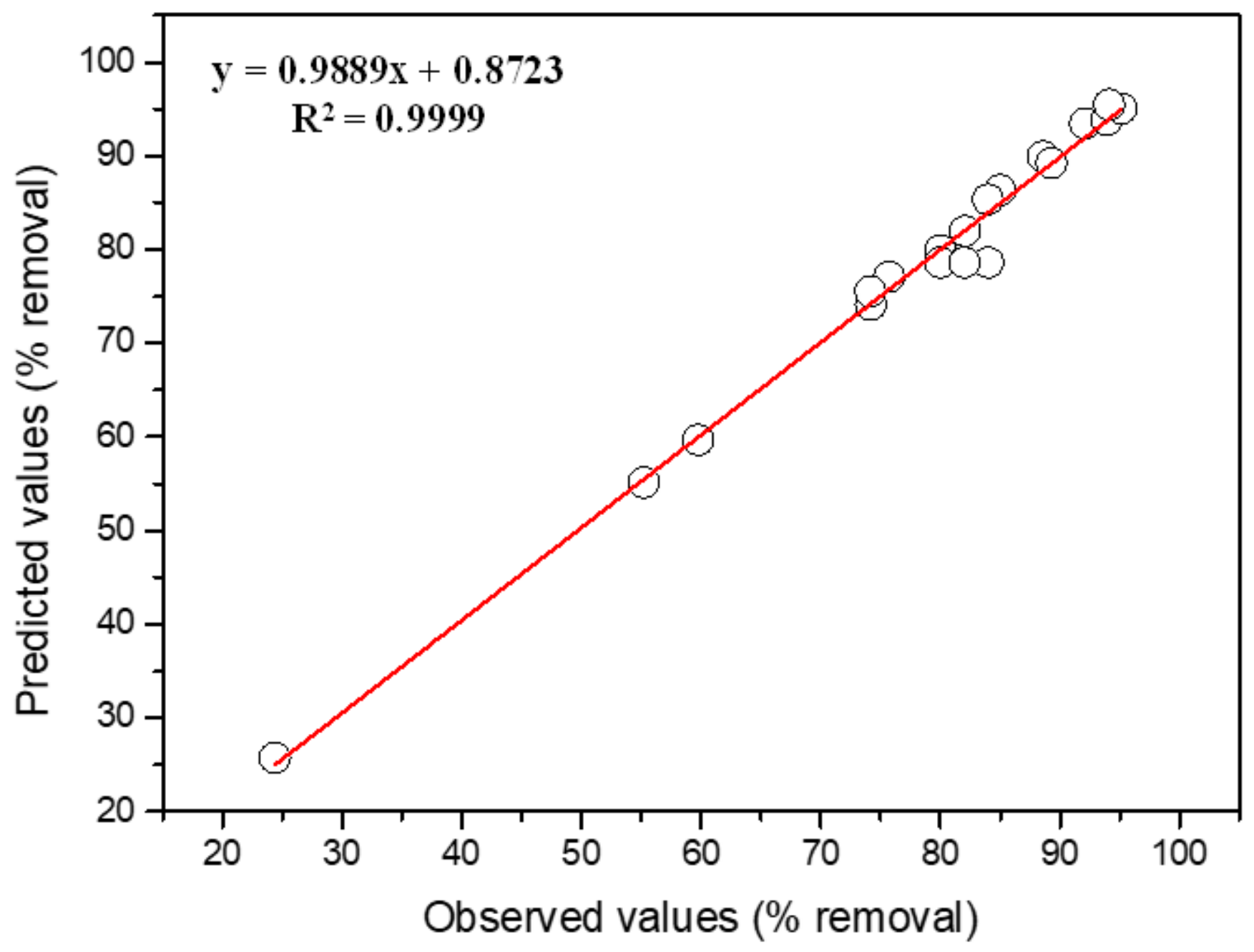

Figure 3

Observed values versus predicted values, for linear model in function of the \% Sb removal. 


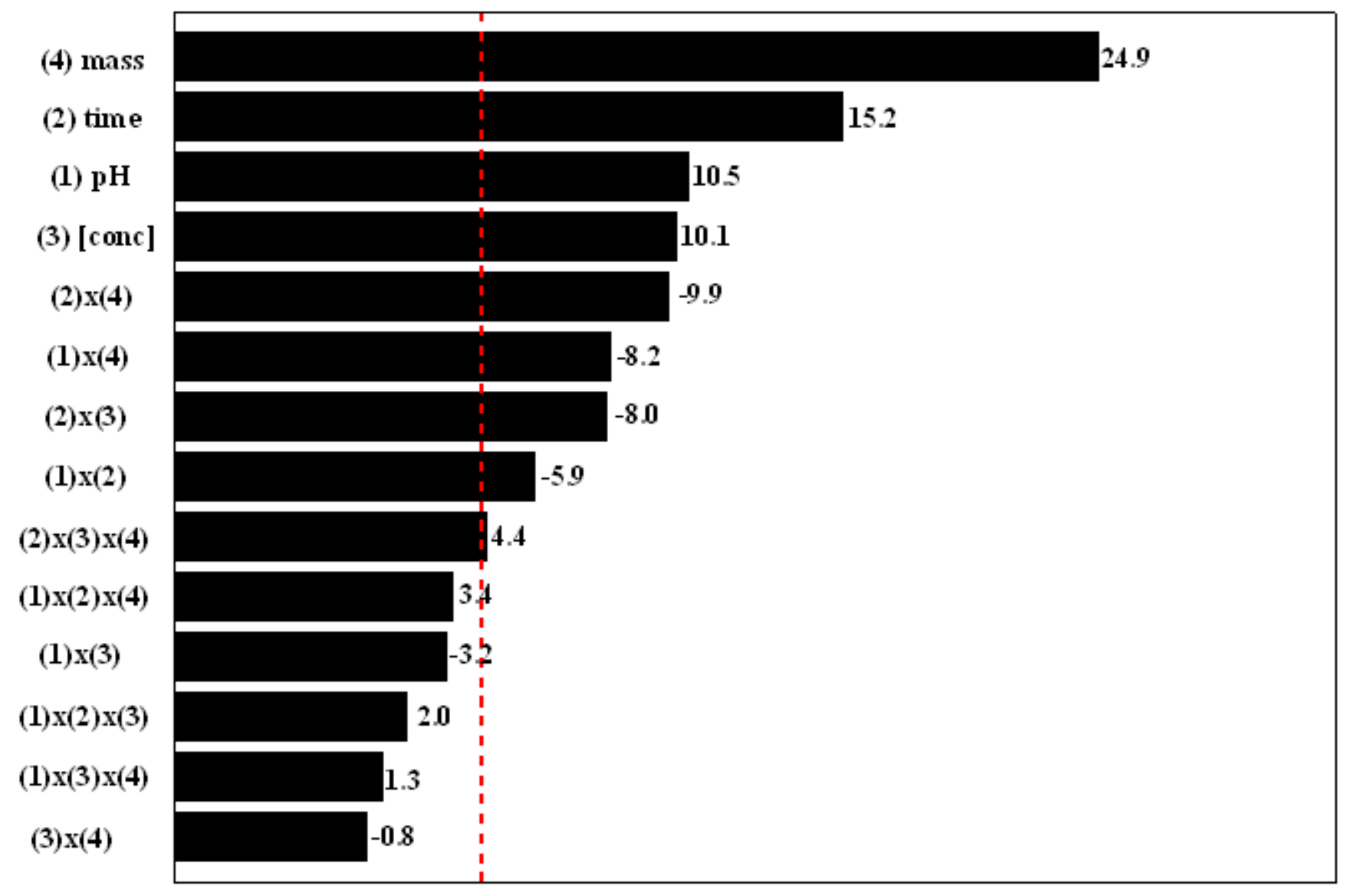

Figure 4

Pareto graphic of effects for full factorial design, in function of the \% Sb removal. 


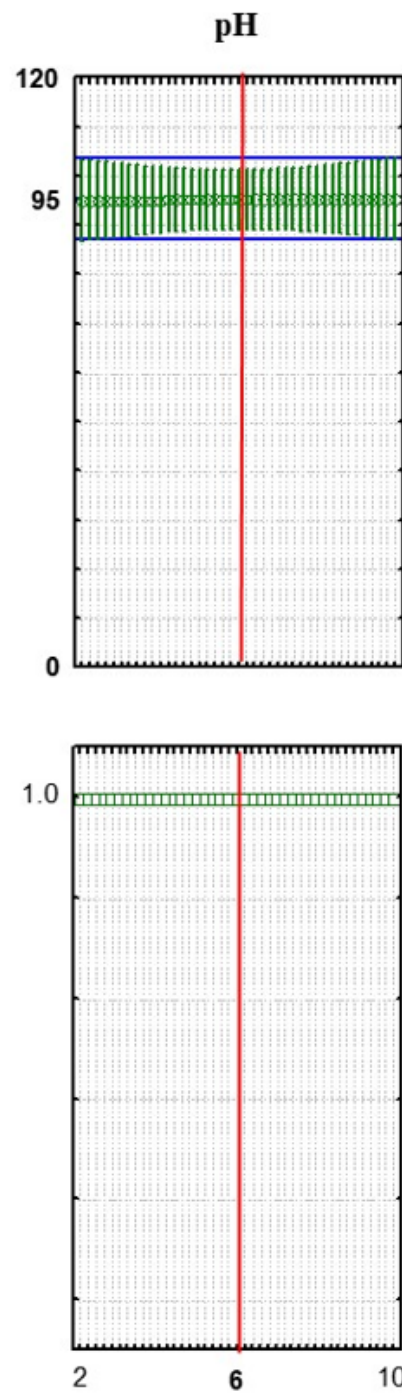

Concentration $\left(\mathrm{mol} \mathrm{L}^{-1}\right)$
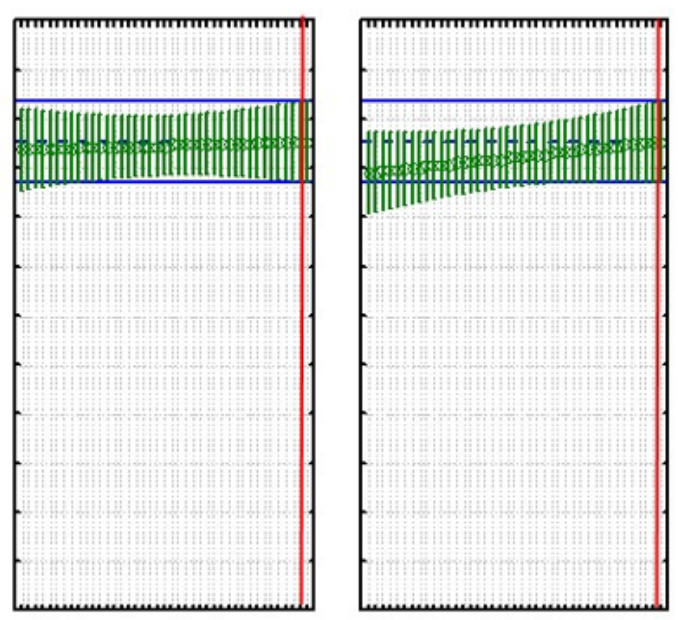

Adsorbent mass (mg)
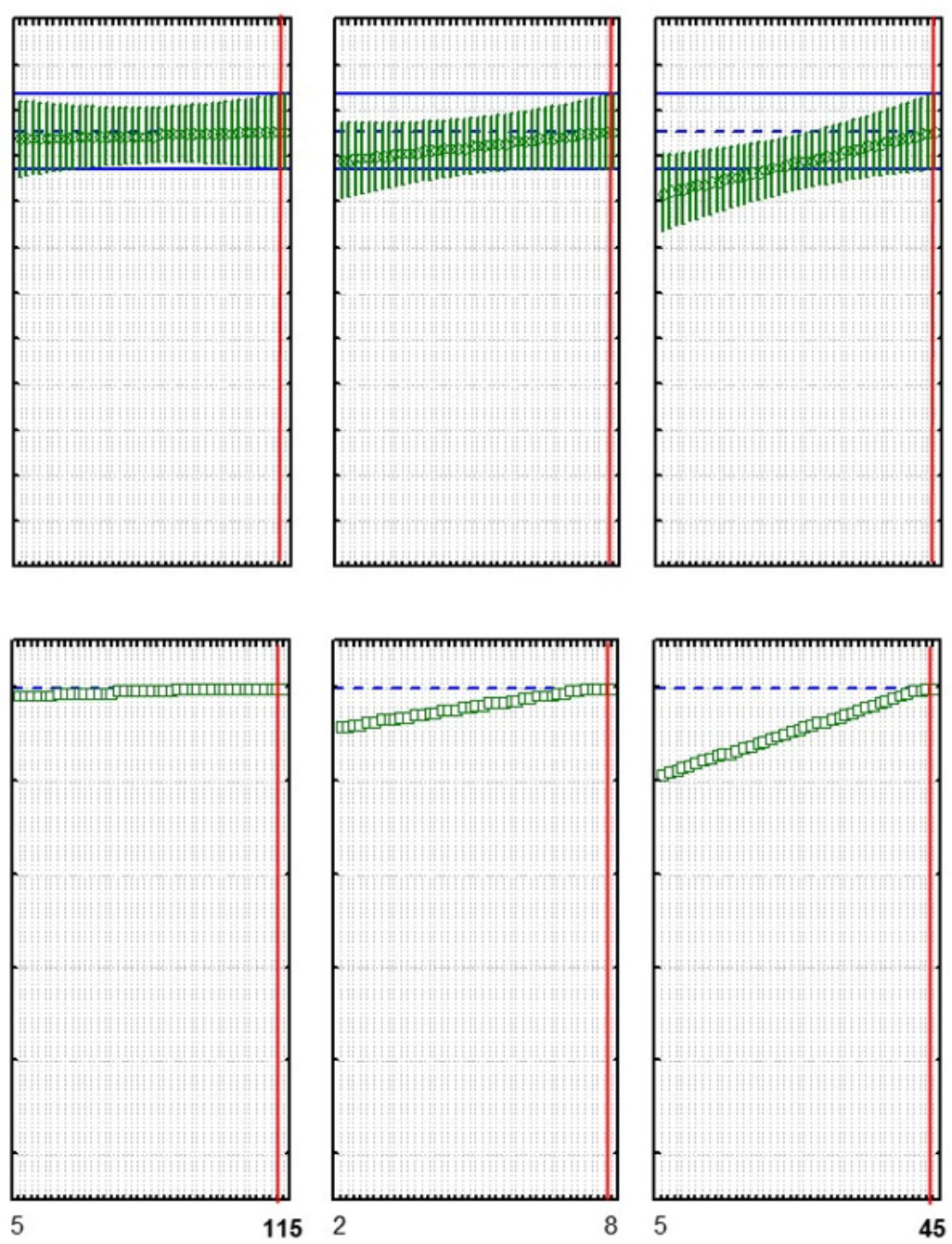

\section{Desirability}

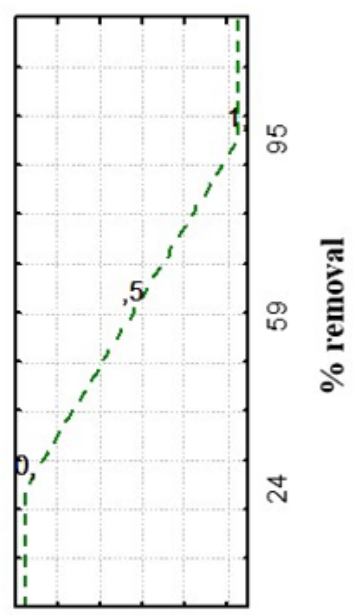

5

\section{Figure 5}

Graphic of profiles of predicted values and desirability in function of the \% Sb removal. 